\title{
METHODOLOGICAL APPROACH TO DETERMINING THE MAIN FACTORS FOR THE DEVELOPMENT OF CREATIVE THINKING IN STUDENTS OF CREATIVE PROFESSIONS
}

\author{
Myroslav KRYSHTANOVYCH (D) ${ }^{1, ~}{ }^{*}$, Svitlana KRYSHTANOVYCH (D) ${ }^{2}$, \\ Liudmyla STEPANENKO (D) ${ }^{3}$, Yuliia BRODIUK (D) ${ }^{4}$, Alina FAST (D) 5 \\ ${ }^{1}$ Department of Pedagogy and Innovative Education, Institute of Law, Psychology and Innovative \\ Education, Lviv Polytechnic, Stepana Bandera str. 12, Lviv Region, 79000 Lviv, Ukraine \\ ${ }^{2}$ Department of Pedagogy and Psychology, Faculty of Postgraduate and Correspondence Education, \\ Lviv State University of Physical Culture named after Ivan Bobersky, Tadeusz Kosciuszko str. 11, \\ Lviv region, 79050 Lviv, Ukraine \\ ${ }^{3}$ Academy of Managerial Staff in Culture and Arts, Lavrska str. 9, 02000 Kyiv, Ukraine \\ ${ }^{4}$ Department of Ukrainian and Foreign Literature and Teaching Methods of Educational Work, \\ Faculty of Philology, Gryhorii Skovoroda State Pedagogical University in Pereyaslav-Khmelnytskyi, \\ Sukhomlynskoho str. 30, Pereyaslav, Kyiv Region, 08400 Kyiv, Ukraine \\ ${ }^{5}$ Department of Social and Humanitarian Education, Educational and Scientific Institute of Pedagogy, \\ Communal Institution of Higher Education Dnipro Academy of Continuous Education, \\ 49006 Dnipropetrovska obl., Dnipro, Chechelivskyi region, Antonovycha str. 70, Dnipro, Ukraine
}

Received 23 February 2021; accepted 24 August 2021

\begin{abstract}
The phenomenon of a person's creative thinking, as well as the mechanisms of its development, are in the problematic field of research of numerous scientists for many centuries. The relevance of these problems was reinforced in many respects by the desire of a person to understand his capabilities, to use them in order to create a comfortable environment around him. Interest in this problem at this stage of socio-historical development has its own special features. The questions that are raised in the study are what factors have the most significant influence on the development of creative thinking in students of creative professions. The main purpose of the article is to determine and compile the key factors for the development of creative thinking in students of creative professions as the main guarantee of their success. To do this, we have applied the methodology of the graph connections between the main factors, which will allow us to form a methodological approach to the hierarchical ordering of the most important factors in the development of creative thinking in students of creative professions as the main guarantee of their success. The subject of the research is the factors of influence on the creative thinking of students of creative specialties. The results of the study led to the formation of the key factors influencing the development of creative thinking among students of creative professions through expert analysis and a survey of specialists in this field and literature. The practical value of the study is to determine the key factors of influence on the development of creative thinking in students and the possibility
\end{abstract}

*Corresponding author. E-mail: mf0077@ukr.net

Copyright (c) 2021 The Author(s). Published by Vilnius Gediminas Technical University

This is an Open Access article distributed under the terms of the Creative Commons Attribution License (http://creativecommons. org/licenses/by/4.0/), which permits unrestricted use, distribution, and reproduction in any medium, provided the original author and source are credited. 
of using the proposed methodological approach, in particular. The study has limitations and they consist because the process of determining the key factors for the development of creative thinking in students of creative professions took place only considering the specifics of the activities of educational institutions in Ukraine.

Keywords: creative professions, creativity, critical thinking, influencing factors, students.

\section{Introduction}

The fourth industrial revolution brought a significant transformation of the labour market. In the materials of the World Economic Forum in 2018, it was noted that its interaction with other socio-economic and demographic factors creates changes in business models in all industries, leads to the emergence of new categories of jobs that will partially or completely push others out. The skill set required for both old and new professions is changing in most industries and changing the way people work. Under these conditions, the requirements for the results of higher professional education and its goals are undoubtedly transformed. Despite the fact that the future requires us to train creative individuals with flexible thinking, capable of innovative changes, the issue of forming appropriate competencies in them in the learning process is on the agenda. Higher vocational education should focus efforts on educating a generation of innovators for the domestic economy as the main condition for its growth and improving the quality of life of the population.

The development of the creative component in the learning process is largely due to implementing special practical tasks. In particular, students are invited, first of all, to carry out a decomposition of a certain pedagogical system of vocational training, requires them to know the basics of a systematic approach, an understanding of the essence of the profession they are mastering, a spatial vision of the problem. After getting acquainted with the basics of the competence-based approach and the essence of the creative process, they are invited to develop the content of individual components of a certain competence as part of the competence model of a specialist in a certain professional direction.

The formation of a creative personality is one of the tasks of modern higher education, in the solution of which an important aspect is the development of creativity in a future specialist. The problem of creativity has been actively studied for several decades, showing different positions in approaches to its study, ambiguous conclusions and assessments, including the possibility of developing creative abilities.

The development of students' creative thinking depends on their aesthetic tastes, intellectual potential inherent in man by nature. Creativity is considered by us, as a concept, actualizes non-standard in identifying creative potential. Creativity is formed by external factors, thanks to the introduction of modern newest creative methods, but it is quite possible to teach students to think in stereotyped, clichéd formulas, and individually, outside the box. To do this, you should organize work both with ready-made texts and with writing your own statements on non-standard topics. An important condition for the effective implementation of the latest technologies is the ability of teachers, who are entrusted with this task, to change the emphasis in teaching methods, their readiness for outputs based on new principles. Indeed, the success of pedagogical activity will largely depend on the psychological readiness of 
the teacher to accept the new, to accept it and to be confident in the correctness of the chosen path. The transformation of the traditional system of teacher-student relations, the change in the role of the teacher, who should play the role of a mentor, will ensure the fundamentality of education, which is a tool for achieving scientific competence.

The age characteristics of students are characterized by a high level of generalization and abstraction compared to secondary school students, an increase in the tendency towards the reasons for explaining phenomena, the ability to reason and prove their own opinion, substantiate conclusions, tie facts and phenomena studied into a single system. The intellectual level of students allows them to carry out a deep analysis of the material, reveal patterns, and identify analogies. The style of mental activity at this age acquires an active, independent and creative character; theoretical thinking is formed. Thinking is the process of reflecting objective activity in ideas, judgments, concepts that occurs in the course of its analysis and synthesis from sensory cognition on the basis of practical activity; it is a mental process of independent search and discovery of an essentially new (that is, new in relation to the initial, previous stages of the cognitive activity of a particular individual). Any learning, in whatever forms it is carried out, is always a necessary and irreplaceable condition for the formation and development of thinking. The assimilation and formation of knowledge is a product of thinking. Creative thinking is the highest form of productive thinking. This type of thinking is characterized by the creation of a subjectively new product and new formations. The product of creative thinking is characterized by uniqueness. Creative professions and people who are involved in them like no one else should develop their own creativity.

It is important to add that all the participants every day deal with students of different creative specialties, and determined only general psychological factors of influence on the development of creative thinking in students. This is due to the fact that the authors' attempt to create a list of general factors of influence on students of creative specialties.

The study has limitations, since it was conducted only on the territory of Ukraine with the involvement of Ukrainian specialists, who took into account the peculiarities of the student body of only one country. In the future, the goal of the authors is to study these factors in other countries.

\section{Literature review}

Research into the importance of creative thinking to students has worried the scientific community for many years. We can talk about the versatility of scientific research in this area.

For example, Kryshtanovych et al. (2021), proposed their own methodological approach to modeling the main ways of increasing creativity in psychology students as the main factor in their professional development. In the course of their research, the model for the development of creativity was tested by introducing it into the educational process of a higher educational institution. As a result, it was found that the use of the system for the development of creativity in psychology students is a positive practice and contributes to their further professional development. As you can see, the issues of the development of students' creativity are raised by scientists in the context of their further professional development. We agree with this thesis and also strive to make our scientific contribution to the development of this issue. 
Feist (2010), and Langebæk et al. (2020) considered the essence of the personality function in creativity, its nature as such. Creativity and creative thinking are practically brother and sister because they are closely related. That is why, we also decided to consider the peculiarities of the development of creative thinking in students of creative professions.

The essence and nature of creativity, considered by Sternberg (2001), which cannot be taken into account in the scientific study of creativity. In his opinion, creativity cannot be considered some special characteristic of cognitive processes, but is one of the deepest characteristics of a person. He also notes that creativity is one of the most determining factors in the success of creative people. In his opinion, direct teaching of creativity is impossible, but it is quite possible to create conditions that stimulate or inhibit creative activity.

In this area were the researches that Ling and Cheong Loh (2020), and Navickiene et al. (2019) examining this relationship between creativity and creative thinking in students and teachers. In their works, they determined that it is the teacher who is one of the most important figures, for many years unites the development of a person's creativity and the acquisition of other scientific disciplines. In our opinion, creative thinking is fully revealed in the student years, therefore, in our research, we chose them as an object of study.

A similar opinion and Mareque et al. (2019), and Burkšaitienè (2018), who just as the object of their own research and took the peculiarities of the development of creativity of students. Here it is necessary to pay attention to the fact that, despite their contribution, there is still no approach that would allow identifying and ordering the factors that contribute to the development of creativity.

Trying to better "measure" the level of creativity among students has been a research question for many scholars. For example, Allwood and Selart (2001), almost two decades ago, tried to achieve this and offered their ideas and solutions to this problem. Kalpokas et al. (2020), presented how the so-called "I" algorithm of students can be formed and how it can be related to their creativity. In our opinion, today it is more relevant under the influence of several factors, to determine and model their influence on the development of creative thinking in students.

In their works, Karavanova Zhalalovna et al. (2020), made the first attempts to develop a system for the development of creativity among students of higher educational institutions. Their creativity development system is based on a number of approaches. And in our opinion, the use of established and unchanging approaches to each student contradicts their main goal - the development of individual creativity. That is why, in our opinion, the use of the primary system for the development of creativity and the provision of teachers directly to introduce and adjust the system for the development of creativity is the most correct solution.

How creativity is used and developed in pedagogical practice in general has been the object of research in no less than other spheres. Mansoor (2010), Zacher and Johnson (2015), Beghetto and Kaufman (2014), Faraj et al. (2018), and Hu et al. (2017), addressed this aspect and tried to solve its main problems. Today, educators and teachers of subjects related to the creative professions understand that a different approach is needed here and that the same creativity in teaching needs to be shown. Unlike other studies, we propose to determine which factors best contribute to the development of creative thinking in students and to apply them more in teaching practice, respectively. 
How students and pupils can be managed through the use of creativity has also had its share of attention among the scientific community. James (2015), is just doing this kind of research. But in our opinion, one should not influence students through a creative or creative approach, but one should try to find how to develop it in themselves.

We believe that the search for factors influencing the development of creativity in students is an extremely important problem, but this is not all. These factors should be assessed and determined, influencing the largest on the development of creative thinking in students, and which are not. That is why the formation of a methodological approach that would contribute to this is relevant today.

It is important to add that all the participants every day deal with students of different creative specialties, and determined only general psychological factors of influence on the development of creative thinking in students. This is due to the fact that the authors' attempt to create a list of general factors of influence on students of creative specialties.

\section{Methodology}

\subsection{Formation a sample of respondents for the study}

To begin with, we, through the use of the method of expert analysis, determined the list of factors, in their opinion, most of all affect the development of creative thinking in students of creative professions. In general, the methods of expert assessments are part of the vast field of decision-making theory, and also expert assessment is a procedure for obtaining an assessment of a problem based on the opinion of specialists (experts) with the aim of further making a decision (choice).

Due to a number of problems associated with the pandemic, the possibility of getting in touch was only within Ukraine and its educational institutions. We have selected 10 leading specialists-trainers of creative thinking among young people, 5 psychologists and 5 teachers of creative specialties from the leading educational institutions of Ukraine.

We have chosen the survey method for the reason that the development of creative thinking is a rather subjective process and here it is the attitude to creativity of the people who are involved in this development that is decisive. That is why the survey, according to the authors, is the most successful research method. The selection of participants was carried out according to the following criteria:

- work experience with students of creative professions for at least 5 years;

- took an active part in scientific research;

- work with exactly the age category of students.

They were asked about the factors, in their opinion, can more influence the development of creativity in students of creative professions and why. The detailed answers we received allowed us to arrive at a middle-arithmetic list. Unfortunately, the respondents asked to remain anonymous, and this right remains with them.

The questions that were asked to the experts met the following requirements:

- were clearly formulated in generally accepted terminology;

- the wording of the question excluded any semantic ambiguity;

- the question logically corresponded to the structure of the forecasting object;

- each question consisted of only one part. 
These factors were determined for higher educational institutions with specialties that are directly related to creativity. For this, we attracted not only teachers, but also psychologists and trainers for the development of creative thinking, since a student of a creative specialty is a person who is on the verge of graduation and starting work, therefore not only teachers were involved in this survey.

\subsection{Methods}

Determination of the main factors influencing the development of creative thinking among students of creative professions is only the first stage. Also, it is necessary to determine which of the factors that have the most significant impact in order to stimulate them. For this, we propose to form a model of hierarchical ordering of the main factors of influence on the development of creative thinking in students of creative professions. Of all the methodologies, this allows to most accurately organize the impact of given parameters. For this, it is necessary to apply a graph of connections between these factors, which are formed on the main use of graph theory. It should be noted that graph theory is one of the key branches of mathematics that studies the properties of graphs. In general, a graph is a geometric configuration that includes points connected by lines.

The use of graph theory is found in scientific works of various fields, it can be informatics, pedagogy, psychology, management and logistics. As an example, in the field of educational and psychological research, we use the theory of networked systems. A network is a generalization of the concept of a graph and is a graph where each edge is assigned a certain number, which is called the "edge weight" and this number has a certain value.

The list of the main factors that were determined as a result of the conducted expert analysis and literature on the development of creative thinking in students of creative professions is shown in Table 1. They will become the initial data for building our model, presented in the next paragraph of this article.

To form a correct data collection system and implement the proposed methods, in the context of pandemic restrictions, the following tools were used:

- remote communication using online and telephone communication;

- conducting a remote survey.

Table 1. The list of the main factors that have the most impact on the development of creative thinking in students of creative professions (source: created by authors)

\begin{tabular}{|c|l|c|}
\hline $\begin{array}{c}\text { Mathematical } \\
\text { notation }\end{array}$ & \multicolumn{1}{|c|}{ Risks } & $\begin{array}{c}\text { Mnemonic } \\
\text { name }\end{array}$ \\
\hline$Z_{1}$ & Formation of non-standard situations during study & FNS \\
\hline$Z_{2}$ & Enhancing the cognitive process in an educational institution & ECP \\
\hline$Z_{3}$ & Creative approach of the teacher & CAT \\
\hline$Z_{4}$ & Openness of the team & OOT \\
\hline$Z_{5}$ & Liberty in teaching your own thoughts & LTT \\
\hline$Z_{6}$ & $\begin{array}{l}\text { Constant training for the development of attention and memory in } \\
\text { the student }\end{array}$ & CTD \\
\hline$Z_{7}$ & Communication of creative tasks & CCT \\
\hline
\end{tabular}


The systematization and analysis of the results, the necessary mathematical and statistical calculations were performed using the Microsoft Excel.

For the hierarchical ordering of factors influencing the development of creative thinking, tools of mathematical modeling and display of results were used due to the use of tools through Microsoft Visio.

The survey was conducted in compliance with all ethical standards requiring scientific research. All survey participants remained anonymous throughout the study; participation in the study did not in any way affect their future professional activities. All research results are only of a scientific nature and therefore, within the framework of ethical standards, do not provide for use in other areas of activity.

For the purpose of the lawful use of the information, all respondents were warned that the assessment will take place exclusively for scientific research and publication in the journal. The proposed methodology was used exclusively to demonstrate and identify the main factors influencing creative thinking of creative thinking. The information contained in this study is not used for other publications.

The information obtained during the study is an indirect and subjective result and may differ when surveyed with the involvement of other experts, but our goal was not only to obtain a list of factors influencing the development of creative thinking, but to demonstrate the effectiveness of the methodology of hierarchical ordering in this area.

\section{Research results}

Suppose that the set of certain factors influencing the development of creative thinking in students is a set $Z=\left\{z_{1}, z_{2}, \ldots z_{n}\right\}$. From this aggregate, we will select $Z_{1} \in Z_{2}$ a number of significant factors. For clarity, we will supplement the mathematical designation of each factor with its mnemonic name (Table 1).

At the first stage, the subset of threats $Z_{1}$ and possible interrelationships between them, we represent in the form of a directed graph (Figure 1), at the vertices of which the elements of the subset $Z_{1}$ are located, the arcs connect the sum of the pairs of vertices $z_{i}$, $z_{j}$ for which the connection is defined. It shows a certain dependence of one threat (beginning of the arrow) on another (end of the arrow).

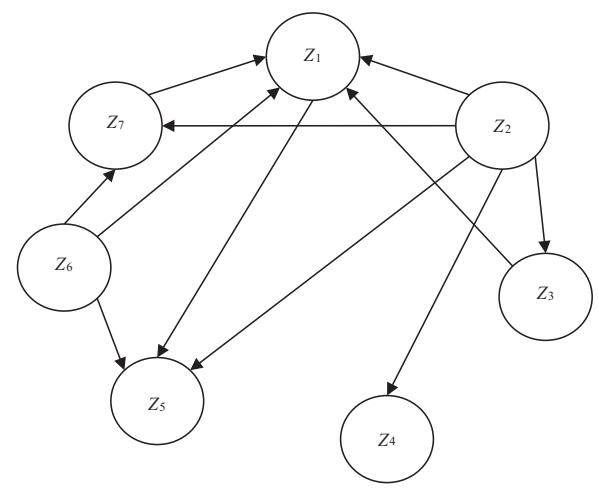

Figure 1. Graph of connections between the key factors of influence on the development of creative thinking in students of creative professions (source: created by authors) 
Based on the constructed graph, we construct a binary dependence matrix $A$ for the set of vertices $Z_{1}$ as follows (1):

$a_{\mathrm{ij}}=\{1$, if the criterion (vertex) $i$ does depend on the criterion (vertex) $j$;

$\{0$, if the criterion (vertex) $i$ does not depend on the criterion (vertex) $j$ :

$a_{i j}$ - binary dependence matrix for the set of vertices $Z_{1}$.

We place the matrix $A$ of $7 \times 7$ elements in the table, adding to it an information row and a column with the names of factors influencing the development of creative thinking in students (Table 2).

Table 2. Binary dependency matrix (source: created by authors)

\begin{tabular}{|c|c|c|c|c|c|c|c|c|}
\hline & \multirow{2}{*}{} & 1 & 2 & 3 & 4 & 5 & 6 & 7 \\
\cline { 3 - 9 } & & FNS $^{*}$ & $\mathrm{ECP}^{*}$ & $\mathrm{CAT}^{\star}$ & OOT $^{*}$ & LTT $^{*}$ & CTD $^{*}$ & CCT $^{*}$ \\
\hline 1 & FNS $^{*}$ & 0 & 0 & 0 & 0 & 1 & 0 & 0 \\
\hline 2 & ECP $^{*}$ & 1 & 0 & 1 & 1 & 1 & 0 & 1 \\
\hline 3 & CAT $^{*}$ & 1 & 0 & 0 & 0 & 0 & 0 & 0 \\
\hline 4 & OOT $^{*}$ & 0 & 0 & 0 & 0 & 0 & 0 & 0 \\
\hline 5 & LTT $^{*}$ & 0 & 0 & 0 & 0 & 0 & 0 & 0 \\
\hline 6 & $\mathrm{CTD}^{*}$ & 1 & 0 & 0 & 0 & 1 & 0 & 1 \\
\hline 7 & $\mathrm{CCT}^{*}$ & 1 & 0 & 0 & 0 & 0 & 0 & 0 \\
\hline
\end{tabular}

${ }^{*}$ Note: FNS - formation of non-standard situations during study; ECP - enhancing the cognitive process in an educational institution; CAT - creative approach of the teacher; OOT - openness of the team; LTT - liberty in teaching your own thoughts; CTD - constant training for the development of attention and memory in the student; CCT - communication of creative tasks.

Based on the matrix $A$, we build the reachability matrix. We form a binary matrix $(I+A)$, where $I\left(b_{i j}\right)$ is the identity matrix and raise it to a certain degree $k$ so that the condition is satisfied as a result. As a result, the reachability matrix must satisfy condition (2):

$$
(I+A)^{k-1} \leq(I+A)^{k}=(I+A)^{k+1} .
$$

The actual construction of a binary matrix is reduced to filling in the table (Table 4).

The actual construction of a binary matrix is reduced to filling in a table (Table 3 ) similar to the one given above, the binary elements of which are determined according to the following rule (3):

$$
\begin{gathered}
b_{i j}=\{1, \text { if from } i \text { can get } j ; \\
\{0, \text { in another way: } \\
b_{i j} \text { - binary reachability matrix for the set of vertices } Z_{1} .
\end{gathered}
$$

The vertex $z j$ is reached from the vertex $z_{i}$ if there is a path in the graph (Figure 1) that leads from the vertex $z_{i}$ to the vertex $z_{j}$. Such a top is called reachable. We denote the subset of such vertices by $S\left(z_{i}\right)$. Similarly, the vertex $z_{i}$ is in front of the vertex $z_{j}$ if it reaches its vertex. Let the number of predecessor vertices form a subset $P\left(z_{i}\right)$. 
Table 3. Reachability matrix (source: created by authors)

\begin{tabular}{|c|c|c|c|c|c|c|c|c|}
\hline & & 1 & 2 & 3 & 4 & 5 & 6 & 7 \\
\cline { 3 - 9 } & & FNS $^{*}$ & $\mathrm{ECP}^{*}$ & CAT $^{*}$ & OOT $^{*}$ & LTT $^{*}$ & CTD $^{*}$ & CCT $^{*}$ \\
\hline 1 & FNS $^{*}$ & 1 & 0 & 0 & 0 & 1 & 0 & 0 \\
\hline 2 & ECP $^{*}$ & 1 & 1 & 1 & 1 & 1 & 0 & 1 \\
\hline 3 & CAT $^{*}$ & 1 & 0 & 1 & 0 & 0 & 0 & 0 \\
\hline 4 & OOT $^{*}$ & 0 & 0 & 0 & 1 & 0 & 0 & 0 \\
\hline 5 & LTT $^{*}$ & 0 & 0 & 0 & 0 & 1 & 0 & 0 \\
\hline 6 & CTD $^{*}$ & 1 & 0 & 0 & 0 & 1 & 1 & 1 \\
\hline 7 & CCT $^{*}$ & 1 & 0 & 0 & 0 & 0 & 0 & 1 \\
\hline
\end{tabular}

${ }^{*}$ Note: FNS - formation of non-standard situations during study; ECP - enhancing the cognitive process in an educational institution; CAT - reative approach of the teacher; OOT - openness of the team; LTT - liberty in teaching your own thoughts; CTD - constant training for the development of attention and memory in the student; CCT - communication of creative tasks.

Finally, a section of subsets of reachable and predecessor vertices, that is, subset (3):

$$
R\left(z_{i}\right)=S\left(z_{i}\right) \cap P\left(z_{i}\right),
$$

The vertices that are not reached from any of the vertices of the set $Z_{1}$, the remaining ones, determine a certain level of the hierarchy of the priority of the action of the influence of factors in development of creative thinking in students assigned to these vertices. An additional condition in this case is to ensure equality (4):

$$
P\left(z_{i}\right)=R\left(z_{i}\right) .
$$

Performing the combination of the above actions gives the first level (the lowest in terms of the importance of influencing the process under study) of the hierarchy of factors influencing the development of creative thinking in students. To determine it on the basis of a preliminary matrix, we build a Table 4 .

Table 4. Calculation table for building a model of the hierarchy of factors influencing the development of creative thinking in students (source: created by authors)

\begin{tabular}{|c|c|c|c|}
\hline $\mathrm{I}$ & $S\left(z_{i}\right)$ & $P\left(z_{i}\right)$ & $S\left(z_{i}\right) \cap P\left(z_{i}\right)$ \\
\hline 1 & 1,5 & $1,2,3,6,7$ & 1 \\
\hline 2 & $1,2,3,4,5,7$ & 2 & 2 \\
\hline 3 & 1,3 & 2,3 & 3 \\
\hline 4 & 4 & 2,4 & 4 \\
\hline 5 & 5 & $1,2,5,6$ & 5 \\
\hline 6 & $1,5,6,7$ & 6 & 7 \\
\hline 7 & 1,7 & $2,6,7$ & 6 \\
\hline
\end{tabular}


The second column of this table is the numbers of the unit elements of the corresponding rows of the access matrix, the third is the numbers of the unit elements of the columns of this matrix. Equality (4) is fulfilled for 2 - enhancing the cognitive process in an educational institution and 6 - constant training for the development of attention and memory in the student, these factors refer to a low level of priority of influence on the development of creative thinking among students of creative professions. Further Table 5 we remove lines 2 and 6 , and in the $i$-th columns we delete numbers 2 and 6 .

We get the Table 5, which is the basis for calculating the second iteration of finding the numbers of the influencing factors that determine the next level of the hierarchy.

Table 5. Calculation table for building a model of the hierarchy of factors influencing the development of creative thinking in students (source: created by authors)

\begin{tabular}{|c|c|c|c|}
\hline $\mathrm{I}$ & $S\left(z_{i}\right)$ & $P\left(z_{i}\right)$ & $S\left(z_{i}\right) \cap P\left(z_{i}\right)$ \\
\hline 1 & 1,5 & $1,3,7$ & 1 \\
\hline 3 & 1,3 & 3 & 3 \\
\hline 4 & 4 & 4 & 4 \\
\hline 5 & 5 & 1,5 & 5 \\
\hline 7 & 1,7 & 7 & 7 \\
\hline
\end{tabular}

In the second iteration, equality (4) is fulfilled for the 3 - creative approach of the teacher, the 4 - openness of the team, and 7 - communication of creative tasks. These factors of influence on the development of creative thinking among students of creative professions determine the next level of the hierarchy. Therefore Table 5 delete rows 3, 4 and 7, and in the 2nd and 3rd columns - numbers 3, 4 and 7. Without further calculations, it can be argued that the first ones will occupy the highest level of the hierarchy - formation of non-standard situations during study and 5 - liberty in teaching your own thoughts.

Having arranged the factors of influence on the development of creative thinking among students of creative professions according to certain levels, we get a hierarchically structured model (Figure 2), imitating the priority of their influence.

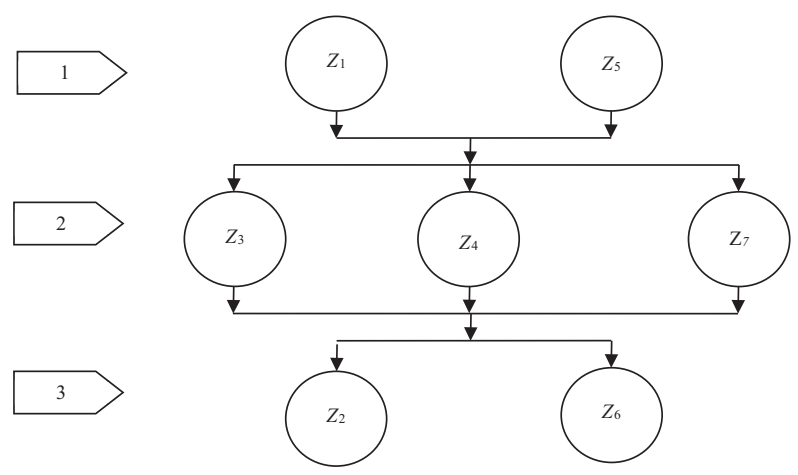

Figure 2. Model of the hierarchy of the impact of factors of influence on the development of creative thinking among students of creative professions (source: created by authors) 


\section{Discussion}

With the development of society, creativity takes an ever higher position in the life of every person. The need for the formation of a creative personality is due, firstly, to the fact that this aspect determines the productive orientation, creative individuality, is the main core of orientation in life; secondly, it is the basic determinant, the foundation of professional creativity; thirdly, it contains conceptual psychological and pedagogical principles of creative teaching and upbringing. A number of scientific works are also looking for ways to develop creative thinking in students. For example, Carvalho and de Oliveira Mota (2010), do this by looking for a way to build student confidence and develop their values of loyalty to their teachers and educational institutions. But in this work, the influence on creativity and general professional development of students was carried out only in the context of internal influence from the educational institution. In our opinion, such a study cannot be considered complete, since higher education institutions are not closed institutions, but rather open systems. In our study, when determining the factors of influence, we took into account the opinion of not only representatives of educational institutions, which, according to the authors, is a significant advantage of the study. Or, Carabine (2013) explores how this is possible through the lens of psychology and sociology. This paper fully presents the study of the development of creativity, but only within the framework of individual development. In our opinion, an important element of the development of creativity is the development of the human sphere in the educational team of a higher educational institution. Our approach is original and provides for more informational support, which can be useful for determining what factors and ways they significantly affect the development of creative thinking in students.

In general, the process of teaching students is a process that must be accompanied by a creative approach. As noted in the works of Khalid et al. (2020), Novak (2009), and Kaplan (2019), teaching should stimulate the creative thinking and skills of students. However, in our research we are trying to raise the question of what factors can attract and contribute to this. In these works, the main emphasis is on the general aspects of the development of creativity, without special specification, in our opinion, it is erroneous, since creativity is already a very subjective phenomenon, and only concretization, specification and determination of the degree of influence of influencing factors, according to the authors, is the most an expedient way of developing creativity among students of creative professions.

Summing up the results of our research, it should be noted that we have proposed a methodological approach that will allow us to determine which factors are the most significant in influencing the development of creative thinking in students of creative specialties and provide the largest impetus to their creative abilities. In our opinion, a teacher, psychologist or trainer who possesses such information will be able to better understand from which side to approach his group of students and stimulate creative thinking.

Taking this into account, the main goal of the study follows - using the theory of graphs and the reach matrix, to determine the degree of influence of each of the factors on the development of creative thinking. The results of our research allow in the future to form an appropriate methodological basis for determining the key factors and parameters for 
stimulating the development of creativity. According to already existing research, we can say that graph theory and reachability matrix have proven to be an effective methodology for determining these parameters.

It should also be noted that the main difference between our study and the existing ones is that, in addition to simply indicating the factors of influence, we determined the level of influence of each of them using a graph of connections and an access matrix, which introduces elements of objectivity into such a subjective process as the development of creative thinking.

As a result of the study, we tried to offer a methodological approach to determining and improving the influence of certain factors on the development of creative thinking in students of creative professions. Thanks to an expert survey, we have identified the most important factors that today influence the development of creative thinking of students of Ukrainian educational institutions. Accordingly, a model of the hierarchy of the influence of the main factors on the creative thinking of students of creative professions has been formed.

The results obtained, according to the authors, are of great scientific importance, since they will allow teachers of higher educational institutions to realize the most significant factors affecting the development of creative thinking, and to strengthen their activities on these factors.

\section{Conclusions}

Taking into account the presentation of the problematics of our research, we can conclude that the problem of developing the creative abilities of students has attracted more and more attention of society for more than a decade, which is associated with the process of increasing the pace of life. Unfortunately, traditional education poses problems for students, in the solution of which, in $70 \%$ of cases, there is an almost mechanical reproduction of the material being studied. This fact is not negative, but the problem is that students develop only one type of thinking, and for independent thinking, two of them are needed.

We can conclude that there are a number of factors that affect the creative thinking of students and they should be taken into account, but at the same time, we can come to the conclusion that creative thinking is inherently a very individual phenomenon and therefore there can be many factors. In conclusion, you should pay attention to the fact that to designate these factors, it is important to use the professional opinion of experts with experience in order to form a basic list of such factors and, in the final version, consider it for modeling, which we did.

Summing up, we can argue that our proposed model takes place in the study of creative thinking and it allows us to streamline the factors influencing this type of thinking in students. It can be concluded that hierarchical ordering allows you to reduce a large number of less important factors and select only those that need to be given the most attention when stimulating creative thinking in students.

This study is qualitative, since the main issue in the study is the degree of influence of each of the factors influencing the creative thinking of students in creative professions, and not the number of such factors. Since we have determined the level of impact for each of the factors, in our opinion, the questions that were posed at the beginning of the study are closed. 
So, formation of non-standard situations during study and liberty in teaching your their thoughts have the greatest impact on the development of creative thinking in students of creative professions. This issue should be addressed in future research.

In the future, this will allow the student to intensify the development of his creative potential, is inextricably linked with their academic performance in the future profession.

\section{References}

Allwood, C. M., \& Selart, M. (Eds.). (2001). Decision making: social and creative dimensions. Kluwer Academic Publishers. https://doi.org/10.1007/978-94-015-9827-9

Beghetto, R. A., \& Kaufman, J. C. (2014). Classroom contexts for creativity. High Ability Studies, 25(1), 53-69. https://doi.org/10.1080/13598139.2014.905247

Burkšaitiene, N. (2018). How can university learning environment contribute to students' creativity? Lithuanian students' perspective. Creativity Studies, 11(1), 162-171. https://doi.org/10.3846/cs.2018.271

Carabine, J. (2013). Creativity, art and learning: a psycho-social exploration of uncertainty. The International Journal of Art and Design Education, 32(1), 33-43. https://doi.org/10.1111/j.1476-8070.2013.01745.x

Carvalho, S. W., \& Oliveira Mota, de M. (2010). The role of trust in creating value and student loyalty in relational exchanges between higher education institutions and their students. Journal of Marketing for Higher Education, 20(1), 145-165. https://doi.org/10.1080/08841241003788201

Faraj, S., Pachidi, S., \& Sayegh, K. (2018). Working and organizing in the age of the learning algorithm. Information and Organization, 28(1), 62-70. https://doi.org/10.1016/j.infoandorg.2018.02.005

Feist, G. J. (2010). The function of personality in creativity: the nature and nurture of the creative personality. In J. C. Kaufman \& R. J. Sternberg (Eds.), The Cambridge handbook of creativity (pp. 113-130). Cambridge University Press. https://doi.org/10.1017/CBO9780511763205.009

$\mathrm{Hu}$, R., Xiaohui, S., \& Shieh, Ch.-J. (2017). A study on the application of creative problem solving teaching to statistics teaching. EURASIA: Journal of Mathematics, Science and Technology Education, 13(7), 3139-3149. https://doi.org/10.12973/eurasia.2017.00708a

James, M. A. (2015). Managing the classroom for creativity. Creative Education, 6, 1032-1043. https://doi.org/10.4236/ce.2015.610102

Kalpokas, I., Sabaliauskaite, E., \& Pegushina, V. (2020). Creating students' algorithmic selves: shedding light on social media's representational affordances. Creativity Studies, 13(2), 292-307. https://doi.org/10.3846/cs.2020.10803

Kaplan, D. E. (2019). Creativity in education: teaching for creativity development. Psychology, 10, 140147. https://doi.org/10.4236/psych.2019.102012

Karavanova Zhalalovna, L., Evgenievich Shishov, S., Mikhaylovna Rozhnova, T., Sergeevna Rozhnova, K., Veniaminovna Polozhentseva, I., \& Petrovna Lobacheva, L. (2020). Development of students' individual creativity in higher education institutions: project based learning. Universidad y Sociedad: Revista Cientifica de la Universidad de Cienfuegos, 12(2), 380-384.

Khalid, M., Saad, S., Abdul Hamid, S. R., Ridhuan Abdullah, M., Ibrahim, H., \& Shahrill, M. (2020). Enhancing creativity and problem solving skills through creative problem solving in teaching mathematics. Creativity Studies, 13(2), 270-291. https://doi.org/10.3846/cs.2020.11027

Kryshtanovych, M., Bilyk, V., Hanushchyn, S., Sheremet, I., \& Vasylenko, K. (2021). Modelling the ways to increase the creativity of psychology students as a basic factor in professional development. Creativity Studies, 14(1), 34-50. https://doi.org/10.3846/cs.2021.12571 
Langebæk, R., Tanggaard, L., Toft, N., \& Berendt, M. (2020). Using creativity as an educational tool in veterinary surgery: students' perceptions and surgical performance. Journal of Veterinary Medical Education, 47(1), 91-99. https://doi.org/10.3138/jvme.1117-175r1

Ling, M. K. D., \& Cheong Loh, S. (2020). Relationship of creativity and critical thinking to pattern recognition among Singapore private school students. The Journal of Educational Research, 113(1), 59-76. https://doi.org/10.1080/00220671.2020.1716203

Mansoor, A. (2010). Teaching creative writing to university level second language learners in Pakistan. New Writing: The International Journal for the Practice and Theory of Creative Writing, 7(3), 201218. https://doi.org/10.1080/14790726.2010.514052

Mareque, M., Prada, de E., \& Pino-Juste, M. (2019). Creativity among business and tourism management university students: determining sociodemographic factors. Creativity Studies, 12(2), 258-279. https://doi.org/10.3846/cs.2019.6925

Navickienè, V., Sederevičiūtè-Pačiauskienè, Ž., Valantinaitė, I., \& Žilinskaitè-Vytienè, V. (2019). The relationship between communication and education through the creative personality of the teacher. Creativity Studies, 12(1), 49-60. https://doi.org/10.3846/cs.2019.6472

Novak, J. D. (2009). Learning, creating, and using knowledge: concept maps as facilitative tools in schools and corporations. Routledge.

Sternberg, R. J. (2001). Teaching psychology students that creativity is a decision. The General Psychologist, 36(1), 8-11. https://doi.org/10.1037/e592592007-003

Zacher, H., \& Johnson, E. (2015). Leadership and creativity in higher education. Studies in Higher Education, 40(7), 1210-1225. https://doi.org/10.1080/03075079.2014.881340 